\title{
Holistic inversion of frequency-domain airborne electromagnetic data with minimal prior information
}

\author{
Ross Brodie ${ }^{1,3}$ Malcolm Sambridge ${ }^{2}$ \\ ${ }^{1}$ Australian National University \& Geoscience Australia, Research School of Earth Sciences, Bldg 61 Mills Road, \\ Acton, ACT 0200, Australia. \\ ${ }^{2}$ Australian National University, Research School of Earth Sciences, Bldg 61 Mills Road, Acton ACT 0200, Australia. \\ ${ }^{3}$ Corresponding author. Email: ross.c.brodie@ga.gov.au
}

\begin{abstract}
The holistic inversion approach for frequency domain airborne electromagnetic data has previously been employed to simultaneously calibrate, process and invert raw frequency-domain data where prior information was available. An alternative formulation has been developed, which is suitable in the case where explicit prior information is not available. It incorporates: a multi-layer vertically-smooth conductivity model; a simplified bias parameterisation; horizontal smoothing with respect to elevation; and cluster computer parallelisation. Without using any prior data, an inversion of 8.0 million data for 3.4 million parameters yields results that are consistent with independently derived calibration parameters, downhole logs and groundwater elevation data. We conclude that the success of the holistic inversion method is not dependent on a sophisticated conceptual model or the direct inclusion of survey-area specific prior information. In addition, acquisition costs could potentially be reduced by employing the holistic approach which largely eliminates the need for high altitude zero-level measurements.
\end{abstract}

Key words: airborne, calibration, electromagnetic, holistic, inversion, MPI, parallelisation.

\section{Introduction}

It is well established that frequency-domain airborne electromagnetic (AEM) data can be adversely influenced by weaknesses in standard in-field calibration procedures. For example, Fitterman (1998) identified potential sources of error in on-ground calibration procedures that result in gain (amplitude scaling) and phase (discrepancy between transmitter and receiver time references) errors. Huang and Fraser (1999) discussed reasons why estimates of system bias (zero-level) based on high altitude observations may not yield accurate results. Furthermore, height (inaccurate altimetry) errors have been noted by Beamish (2002) and Brodie and Lane (2003). These errors, which we collectively call 'systematic calibration errors', must be removed during data processing, or somehow accounted for, if optimal interpretation results are to be achieved.

Data processing usually involves subtraction of high altitude zero-level estimates, filtering to remove short period noise (e.g. powerline noise), and levelling. Levelling is primarily guided by the aim of generating apparent conductivity maps that are spatially coherent and free of artefacts (i.e. features that the processor considers to be non-geological in origin). To remove artefacts the processor chooses to adjust some combination of gain, phase, bias or height parameters. The processing is carried out independently for each frequency and can involve several time consuming sequentially applied correction iterations (Valleau, 2000). Huang and Fraser (1999) noted that poor levelling decisions can generate false features and eliminate real features.

Brodie and Sambridge (2006) argue that because of the complex non-linear relationship between the calibration parameters and the in-phase and quadrature data, and thence the apparent conductivity, it is unlikely that even an experienced processor can choose the correct combination of parameters to adjust. They argue that sequentially applied corrections allow the propagation of errors from one processing step to the next. They consider conventional levelling to be an inherently subjective process, and because levelling is independent for each frequency, it is impossible to identify and correct any inter-frequency inconsistencies that may exist, or to ensure that additional inconsistencies are not introduced. They further argue that, although a degree of optimisation may be achieved through conventional processing, the final result is far from the best that might result from a more objective and systematic approach.

Because of weaknesses in system calibration and data processing procedures it is often found that the data misfit achieved through inversion is unacceptable or that the inversion results are inconsistent with prior information (Deszcz-Pan et al. 1998; Brodie et al., 2004b). Alternative methods of calibrating and processing frequency-domain AEM data have been suggested by Deszcz-Pan et al. (1998), Huang and Fraser (1999), Green (2003) and Ley-Cooper and Macnae (2004).

A further method, called the holistic approach, was outlined by Brodie and Sambridge (2004) and formally described by Brodie and Sambridge (2006), the later of which we hereinafter call Paper 1. The crux of the holistic approach is that the data are simultaneously calibrated, processed and inverted. The parameters of a mathematical model that accounts for systematic calibration errors are solved for in addition to a single conductivity model that covers the whole survey area. By calibrating and inverting all the data at once, rather than in conventional sample-by-sample fashion, the method can fully exploit the anticipated true inter-frequency and spatial coherency of the geological signal in the data.

In contrast to conventional methods, where separate discrete $1 \mathrm{D}$ models are associated with every airborne sample, the holistic approach is used to simultaneously invert the entire airborne 
dataset (plus any available independent conductivity and interface-depth data) to solve for all of the parameters of a 3D model in one procedure. Because the entire set of parameters of the $3 \mathrm{D}$ model are derived simultaneously, the output is quite different to post-inversion stitching together the results of independent $1 \mathrm{D}$ models. It is also important to note that the electromagnetic forward model and derivative calculations are all carried out using 1D local models extracted from the 3D model. This means we are unable to take advantage of sophisticated 3D modelling, however the scheme makes the inversion of large regional datasets computationally feasible, while still outputting a 3D model with controlled spatial coherency.

In Paper 1 the holistic approach was demonstrated to be successful with synthetic and real survey data. It was concluded that the holistic approach: produced superior results in comparison to conventional techniques; that it reduced the subjectivity of data processing decisions; and that it potentially provides cost savings. However, in Paper 1, several downhole conductivity logs and groundwater depth data were available for use as explicit prior information. Reference model constraints were also provided by a sophisticated five layer conceptual model with reliable reference values that were generated from prior statistical constraints. The availability of explicit prior information perhaps made this an ideal situation.

The question remained as to how well the method would perform in a less ideal situation where good prior information is not available, and this is what we investigate in this paper. We first briefly review the holistic inversion formulation and then outline some refinements. These include, a new bias parameterisation and use of lateral roughness constraints that are based on elevation rather than depth. The modified scheme is illustrated with an example where no explicit prior information is used. We also describe how the holistic inversion code has been parallelised so that it can be run in a distributed computing environment thereby making inversion of large datasets possible.

Despite not using explicit prior information in the holistic inversion, we find that the recovered conductivity model is geologically plausible and consistent with downhole logs and groundwater depth data. Zero-levels predicted from the calibration model correlate well with zero-level measurements recorded at high altitude. Gain values are similar to gain values that would be predicted from downhole log data. We conclude that the holistic inversion can be used in many cases where little prior information is available.

\section{Holistic inversion review}

\section{Introduction}

The philosophy behind the holistic approach is as follows. (1) All frequencies are considered together so that the anticipated true inter-frequency coherency of the geological signal can be exploited and any inter-frequency inconsistency can be detected and corrected. (2) All airborne samples are inverted simultaneously so that the expected spatial coherency of the geological signal can be exploited. (3) Calibration, processing and inversion stages are combined into one procedure, ensuring that assumptions made for each stage are consistent. This onestage procedure avoids propagation of errors that can occur when multiple sequential processing steps are applied. (4) The formal inversion approach, where error sources are accounted for, minimises the subjectivity that is inherent in conventional processing schemes. (5) The framework allows a single 3D conductivity model to be derived that is consistent with all the airborne data, independent conductivity data and independent interface-depth data, as well as prior expectation of subsurface conductivity.

\section{Model}

The inversion model consists of the conductivity model and the calibration model. The subsurface is assumed to be comprised of $N$ layers whose conductivity and thickness varies laterally in smooth and continuous fashion. At any horizontal location the conductivity is constant from the top to the bottom of each layer. The natural logarithm of the $N$ layer conductivities and $N-1$ layer thicknesses are parameterised by separate bicubic B-spline meshes. The spline node spacing may be different on each mesh and in each direction, and can be chosen so they adequately represent conductivity variations with as few nodes as possible. The spline node coefficients are the unknown parameters of the calibration model that we solve for in the inversion.

The calibration model comprises gain, phase, bias and height-error terms. There are several possible ways that we could choose to parameterise the calibration model. The choice is guided by knowledge of the types of calibration problems that are expected to exist in the system and how they are expected to vary over time. In Paper 1, we assumed: (1) gain to be constant for each frequency for a complete survey; (2) phase to be constant for each frequency for each day of flying; (3) bias to vary piecewise linearly over a flight for each in-phase and quadrature channel; and (4) height-errors to be constant for all frequencies over a complete survey. For the gain, phase and height-error factors, the unknown parameters in the inversion were simply discrete values for the relevant survey-frequency, survey-frequency-day or survey combination respectively. However the unknown bias parameters were a mixture of bias and bias drift rates.

\section{Observed data}

The three data types considered are, airborne, geoelectric and interface-depth measurements. We use essentially raw AEM data that have not had zero-levels removed or other conventional data levelling corrections applied. We do however pre-apply conventional powerline and sferic removal filters (e.g. $\sim 9$ point median and hanning filtering) and reverse instantaneous level shifts that are sometimes introduced into the data during high-level zero-level calibrations, so that we are left with a continuous record of each channel of information without any discontinuities.

Geoelectric data are independent values for the logarithm of conductivity at specific locations for specific depth ranges. Typically these data will come from downhole conductivity logs or inversions of ground electromagnetic survey data.

Interface-depth data are any information that is available regarding the depth at a specific location to a specific interface in the layered conductivity model. These could, for example, include the depth to standing water level observed in boreholes or depth to basement information.

\section{Forward problem}

To predict data for each airborne sample we first compute the local $1 \mathrm{D}$ vertical conductivity profile $(\boldsymbol{\sigma}, \mathbf{t})$ that is directly below the sample's location from the spline meshes. We then compute the set of local calibration values that are relevant to the sample. For every frequency this involves selection of local gain $(g)$, phase $(\theta)$ and height-error $(\Delta h)$ values from a lookup table and calculation of the local in-phase $\left(b^{i p}\right)$, and quadrature $\left(b^{q}\right)$ biases from the start bias and drift rate parameters of the calibration model. The 
extracted local 1D conductivity profile is forward modelled to produce its 'theoretical' airborne response, which is then transformed to the predicted airborne in-phase $\left(d_{p}^{i p}\right)$ and quadrature $\left(d_{p}^{q}\right)$ data via the calibration model equation,

$$
d_{p}^{i p}+j d_{p}^{q}=g e^{j \theta}\left(\mathbf{s}(\boldsymbol{\sigma}, \mathbf{t}, h+\Delta h)+\left(b^{i p}+j b^{q}\right)\right) .
$$

Here the complex function $\mathbf{s}(\boldsymbol{\sigma}, \mathbf{t}, h+\Delta h)$ is the forward model algorithm, $h$ is the altimeter measured transmitter and receiver loop height and $j=\sqrt{-1}$.

To predict a geoelectrical datum $\left(d_{p}^{g e o}\right)$, we similarly extract the local 1D conductivity profile for the datum's specified location from the spline meshes. We then average the natural logarithm of the 1D profile's conductivity over the datum's specified depth range. Likewise to predict an interface-depth datum $\left(d_{p}^{\text {int }}\right)$, we extract the local 1D conductivity profile and then sum the thicknesses of all layers in the profile that are above the datum's specified interface.

Analytic expressions have been derived for the derivatives of all three data types with respect to the parameters of the conductivity and calibration models; however they are omitted here for brevity.

\section{Inversion}

In the inversion we seek the model that minimises an objective function of the form,

$$
\Phi=\Phi_{d}+\lambda_{r} \Phi_{r}+\lambda_{x} \Phi_{x}+\lambda_{y} \Phi_{y}+\lambda_{z} \Phi_{z}+\lambda_{b} \Phi_{b} .
$$

Here $\Phi_{d}$ is a data misfit term defined in the usual noise-normalised least-squares sense. The term $\Phi_{r}$ quantifies the differences between the inversion model and a reference model, normalised by prior uncertainty. Constraints on the spatial roughness of the conductivity model are imposed through the terms $\Phi_{x}, \Phi_{y}$ and $\Phi_{z}$, which are measures of the second derivative of the conductivity in the east-west, north-south and vertical directions respectively. Similarly, $\Phi_{b}$ is a measure of the roughness of channel biases. The $\lambda$ 's are multipliers that weight the relative importance of each of the terms.

We minimise the non-linear objective function via a linearised gradient-based iterative scheme. We choose a set of initial model parameters equal to the reference model parameters. The model parameters are then iteratively updated, after solving a linear system via the conjugate gradient method at each iteration.

Because we wish to invert all the airborne data for a conductivity model that covers the entire survey area at once, the linear system to be solved is large. However, an important feature of the bicubic B-spline conductivity model parameterisation is that each datum is influenced by just the 16 adjacent spline nodes on each mesh. This means that most of entries in the Jacobian (and other matrices in the formulation) are zero. Therefore sparse matrix algebra and storage algorithms can be employed, making the inversion of large datasets more feasible. We have previously been able to solve systems with up to 575000 data and 148000 parameters on a single desktop computer. In that case we used packages SparseLib++ and IML++ described by Dongarra et al. (1994).

\section{Inversion with minimal prior information}

In Paper 1 we demonstrated the successful application of the method for the case where specific survey-area prior information was available. However, without this information in the form of downhole conductivity logs, ground electromagnetic surveys or interface depths it is difficult to choose a suitable conceptual conductivity model and build an accurate reference model with associated uncertainties. A shortage of prior information may also limit our understanding of the geological layering and how it should be translated to a conceptual conductivity model. In this section we outline how the holistic inversion can be applied when specific prior information for the survey area is not available or is not included directly in the inversion.

\section{Conductivity model parameterisation}

In Paper 1 and in Brodie et al. (2004b), a variable-thickness conductivity model in which each of the five layers corresponded to a specific unit in the well understood conceptual (hydro) geological model, was used. Because reliable strong prior information was available, we could impose tight constraints on the layer properties, which made it possible to solve for the layer thicknesses in a stable manner. In those circumstances, a few-layer parameterisation was a good choice because the model could be tailored to adequately represent the true conductivity variations with a minimal number of unknowns. Furthermore, because the inversion parameters were direct proxies for (hydro) geological features there was no need to carry out additional postinversion manipulations to extract features which downstream users required, such as clay thickness and watertable depth.

However, in the absence of good prior knowledge, there is no way to know how to choose a generic few-layered model that can adequately represent the large possible (but unknown) range of vertical conductivity profile shapes. In such cases, a multi-layer parameterisation is a suitable choice because it can represent a wide range of profile shapes. In this type of parameterisation, particular layers in the model do not correspond to particular geological features. Instead the features must be extracted by some post-inversion manipulation or interpretation. To improve stability it is necessary to fix the layer thicknesses and to regularise the vertical profile shape, with for example, smoothness constraints (Constable et al., 1987). Because we are simulating the case where there is an absence of good prior information, we have chosen to adopt this multi-layer, fixed-thickness, verticallysmooth style of parameterization for the examples presented in this paper.

\section{Conductivity roughness regularisation}

In Paper 1 lateral conductivity roughness constraints were imposed by inclusion of east-west and north-south roughness terms in the objective function that was to be minimised. This required the building of east-west and north-south roughness matrices that were denoted $\mathbf{L}_{x}$ and $\mathbf{L}_{y}$. These matrices were linear second finite difference operators that operated on the natural logarithms of layer conductivities and thicknesses at spatially adjacent spline mesh intersections in the respective directions. Entries in the matrices were in the familiar form

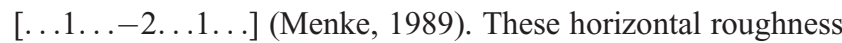
terms promote smoothness of each layer conductivity and thickness, irrespective of layer elevation. Therefore the conductivity was encouraged to be smooth with respect to depth and thus topography. In some geological settings (e.g. where conductivity is controlled by weathering) this is suitable, however in others (e.g. where conductivity is hydrogeologically controlled) it is more reasonable to expect the conductivity to be smooth with respect to elevation.

In this paper, we have chosen to follow the later approach and show by the example in Figure 1 how the roughness matrices are built. A portion of a conductivity model is shown with the position of spline nodes marked on its uneven topographic surface. We denote the conductivity node for the $i$ th layer at the $j$ th node (from the left) as $n_{i, j}$ and its thickness as $t_{i, j}$. To calculate the entries for 


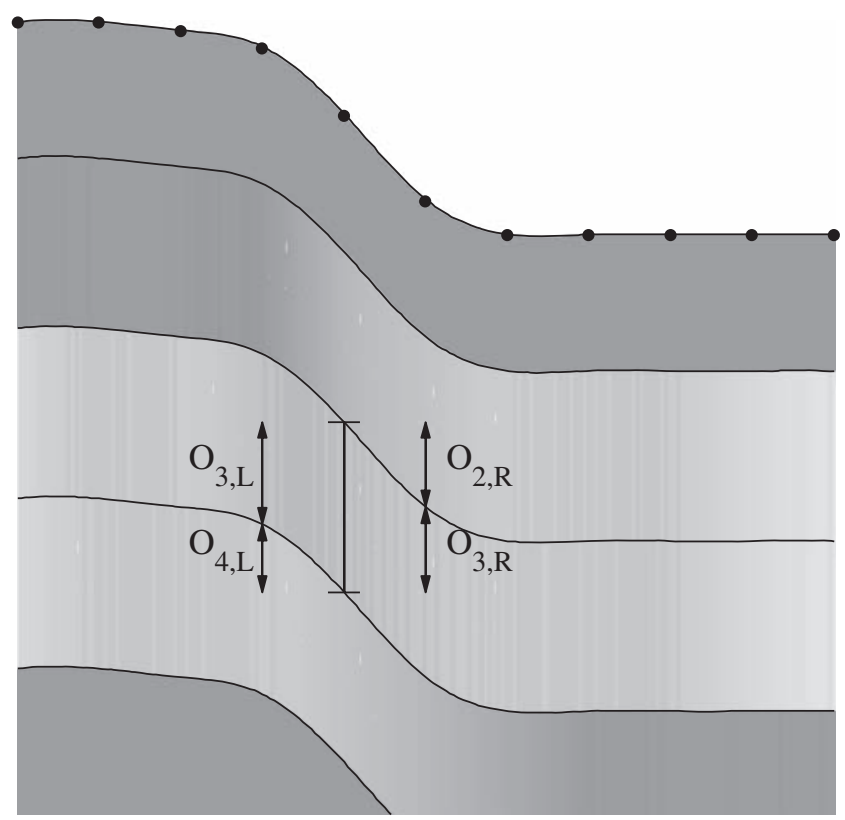

Fig. 1. Portion of a conductivity model showing spline node locations on the topography. The lengths $O_{3, L}, O_{4, L}, O_{2, R}$, and $O_{3, R}$ are overlaps between layers at adjacent spline nodes, required for construction of the horizontal roughness matrices.

the row in the roughness matrices that corresponds to node $n_{i, j}$, we find all layers that, at the adjacent left and right hand nodes, partially span the same elevation range as the $i$ th layer at the $j$ th node, and calculate the amount of layer overlap. For example in the specific case of node $n_{3,5}$ the relevant (i.e. non-zero) overlaps are marked $O_{3, L}, O_{4, L}, O_{2, R}$, and $O_{3, R}$. Therefore entries in the roughness matrices will be in the form $\left[\ldots f_{3, L} \ldots f_{4, L} \ldots-2 \ldots\right.$ $\left.f_{2, R} \ldots f_{3, R} \ldots\right]$, where $f_{a, b}$ are fractional overlap terms defined as $f_{a, b}=O_{a, b} / t_{3,5}$. Typically there will be five non-zero entries in each row of the roughness matrices, however in general there may be more or less non-zero entries depending on the topographic variations and layer thicknesses.

\section{Bias parameterisation and regularisation}

To parameterise the piecewise linear bias variation, in Paper 1 we used the value at the beginning of the flight and drift rates over set time intervals. Here we only use the bias values at set equally spaced time intervals throughout the flight. The advantage is that the number of physically different parameter classes is reduced and the construction of the matrix used for mapping model parameters to reference values is simplified.

\section{Data}

Only AEM data are used. We have not modified the form of the airborne data, its pre-processing or the method of its prediction.

\section{Parallelisation}

The size of the holistic inversion we are able to run on a standalone computer is limited mainly by the available computer memory and to a lesser degree by execution time. For the real data example in Paper 1, the largest dataset we inverted with 2 GB memory and the chosen model parameterisation was a 2590 line km subset of a survey sub-sampled to every 17 th sample $(\sim 50 \mathrm{~m})$. This was by no means an insubstantial AEM dataset size but mapping-style surveys in Australia can be several times larger.
Part of the philosophy of the holistic inversion is to include as much data as possible so that spatial coherency can be exploited, so ideally we would prefer to invert the complete dataset at once. In a multi-layer vertically-smooth parameterisation, we usually require at least twice as many model parameters as in the few-layer parameterisation. We have been motivated by these factors to parallelise the holistic inversion code to allow inversion of complete datasets with a larger number of samples. Parallelisation has allowed us to invert our largest frequency domain AEM dataset (11476 line km) sub-sampled to every fifth value.

The holistic inversion code was parallelised to run on cluster computers under the Message-Passing Interface (MPI) standard (MPI Forum, 1994). The 1D forward modelling and derivative calculation portion of the algorithm scales linearly (i.e. doubling the processors halves the time) because the calculations for all airborne samples can be carried out independently on separate processors without requiring any inter-process communication. We have used the package PETSc (Balay et al., 2005) for sparse compressed row distributed storage of the matrices. This allows us to access $10 \mathrm{~s}$ of gigabytes of random access memory which is not available on a single processor. We have used the conjugate gradient algorithm within PETSc, for solving the sparse linear system in parallel at each iteration. This solver does require interprocess communication and thus does not scale linearly. We therefore choose to use only as many processors as was necessary to access the total required amount of distributed memory.

\section{Results}

We demonstrate holistic inversion using data acquired with the RESOLVE system over the Riverland area in South Australia during 2002. The system was configured in this survey with six coil-sets operating at the frequencies $385,1518,3323,6135$, 25380 and $106140 \mathrm{~Hz}$. The transmitter-receiver separation was $7.86 \mathrm{~m}$ for the five horizontal coplanar coil sets, and $8.99 \mathrm{~m}$ for the single vertical-coaxial $(3323 \mathrm{~Hz})$ coil set. The survey was flown with a nominal bird height of $30 \mathrm{~m}$ along north-south flight lines spaced mainly at $150 \mathrm{~m}$, but at $300 \mathrm{~m}$ in part of the area. East-west tie lines were flown at $\sim 6 \mathrm{~km}$ spacing.

This dataset has been the subject of several previous studies. Brodie et al. (2004a) and Ley-Cooper and Macnae (2004) identified calibration problems in the Riverland dataset. Brodie et al. (2004b) inverted the dataset with conventional 1D sampleby-sample inversion. In Paper 1, we applied the holistic inversion to a subset of the Riverland dataset. As discussed earlier, we used a conductivity model with five layers each having a variable conductivity and thicknesses. A five layer model was appropriate in that case. Each layer corresponded to a layer in our conceptual geoelectrical model. We had sufficient prior information to generate a reliable reference model and we used geoelectric (downhole conductivity logs) and interface-depth (groundwater depths) data as explicit constraints.

In this paper, the entire 11476 line $\mathrm{km}$ of airborne data subsampled to every fifth sample $(\sim 18 \mathrm{~m})$ were inverted. The input airborne data were raw except for the aforementioned reversal of instantaneous level shifts that are sometimes introduced during high altitude zero-level observations, and powerline filtering to remove powerline and sferic effects. A small percentage $(0.27 \%)$ of data were excised in zones where the filters did not adequately removed powerline and sferic noise. There were 89 flights, and 597 lines in the airborne dataset acquired during 37 days of flying. We did not use geoelectrical or interface-depth data even though they were available. There were 8078352 data in total; made up of 673196 airborne samples each having 12 channels. We used 
the estimates of airborne data uncertainties shown in Table 3 of Brodie et al. (2004b) that were derived from analysis of repeat line data (Green and Lane, 2003).

The alternative multi-layer parameterisation of 20 layers with fixed thicknesses was used throughout the inversion. The layers get progressively thicker with depth, from $1.5 \mathrm{~m}$ for layer one to $9.0 \mathrm{~m}$ for layer nineteen, while the bottom layer is infinitely thick. A node spacing of $100 \mathrm{~m}$ is used in both horizontal directions for every layer conductivity mesh. There were 3404788 unknowns in total, of which 6768 were calibration (6 gain, 222 phase and 6540 bias) parameters. We did not have reason to believe that there were systematic height errors present in this dataset so we did not solve for height-errors.

A homogenous $0.5 \mathrm{~S} / \mathrm{m}$ conductivity reference model was used. We specified an extremely large standard deviation (prior uncertainty) of 200 natural logarithm units for these reference values so that a very wide range of conductivities were permitted. Reference values of 1.0, 0.0 degrees and $0.0 \mathrm{ppm}$ were used for gain, phase and bias values, respectively. Standard deviations on the gain and phase parameters were 0.1 and 3.0, and for bias values they were taken from the statistics calculated by Brodie and Sambridge (2006). Vertical roughness constraints were imposed by minimising the second derivative of the vertical conductivity structure. We also used lateral roughness constraints that minimised the second derivative of the conductivity structure in both the north-south and east-west directions. The lateral constraints were imposed by second finite difference matrices constructed as described earlier in the section 'conductivity roughness regularisation'. The degree of smoothing was chosen by initially setting the regularisation weights $\lambda_{x}, \lambda_{y}, \lambda_{z}$, (equation 2) to large values and then reducing them manually until the data were able to be fitted. Roughness constraints were imposed on the estimates of the bias for each channel by minimising the second derivative of the bias with respect to time.

The holistic inversion was run on 64 processors of the Terrawulf computational facility (http://rses.anu.edu.au/ terrawulf) under MPI. Each processor ran at $2.4 \mathrm{GHz}$ and had access to $1 \mathrm{~GB}$ of memory. The total execution time was $8.22 \mathrm{~h}$ and $\sim 51$ GB of memory were required.

Figure 2 demonstrates that there is an excellent match between the gain values estimated from the holistic inversion and the gain

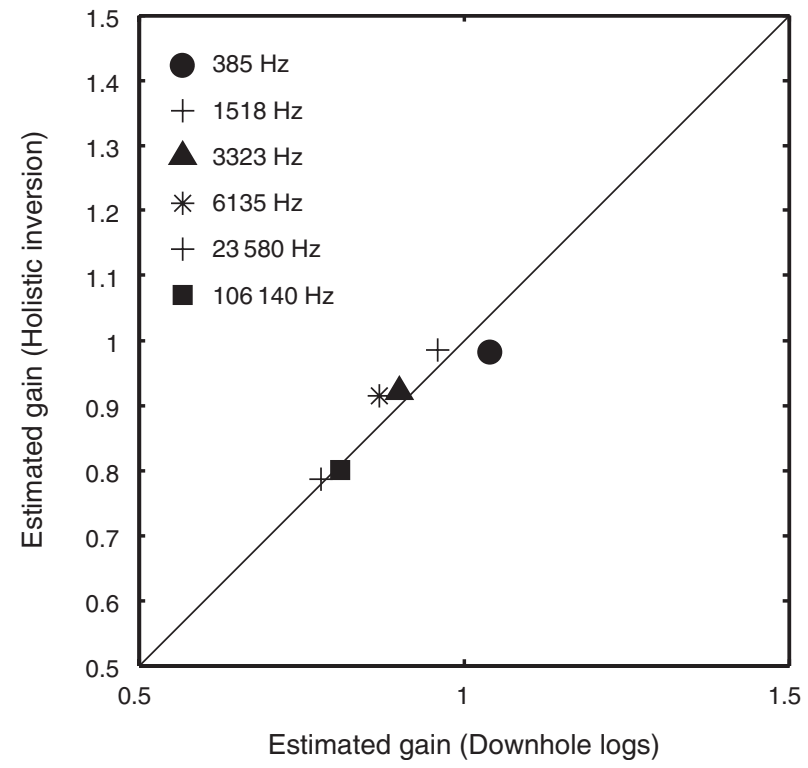

Fig. 2. Gain values estimated from downhole logs versus gain values estimated from the holistic inversion calibration model. values estimated independently from downhole log data (Brodie et al., 2004a).

Under normal circumstances we would use the zero-level values recorded at high altitude as the reference model values for the bias. However in this work they were omitted. Instead, all reference values for bias parameters were set to zero, which allows us to see whether they can be estimated directly from the inversion procedure. A strong correlation is clearly evident in Figure 3, which shows a comparison between the zero-level values recorded at high-altitude and the corresponding bias values estimated from the holistic inversion. As in Paper 1 the greatest discrepancies are in the $106140 \mathrm{~Hz}$ estimates, however in this case the discrepancies are reduced. This may be a consequence of the greater flexibility in the multi-layer-model parameterisation. The good correlation leads us to believe that, under the right conditions, it may be feasible to eliminate high altitude zero-level observations altogether, which would reduce acquisition costs considerably.

A comparison of downhole conductivity log measurements and conductivities estimated from the inversion model is shown in Figure 4 . The data relate to the average conductivity over every $5 \mathrm{~m}$ interval for all the 44 available logs. The correlation is high $\left(R^{2}=0.81\right)$, although the inversion estimates are slightly biased towards higher conductivities. Individual conductivity-depth plots for all $44 \operatorname{logs}$ are shown in Figure 7. Our overall assessment is that the holistic inversion has been able to estimate the vertical conductivity structure well. It appears that
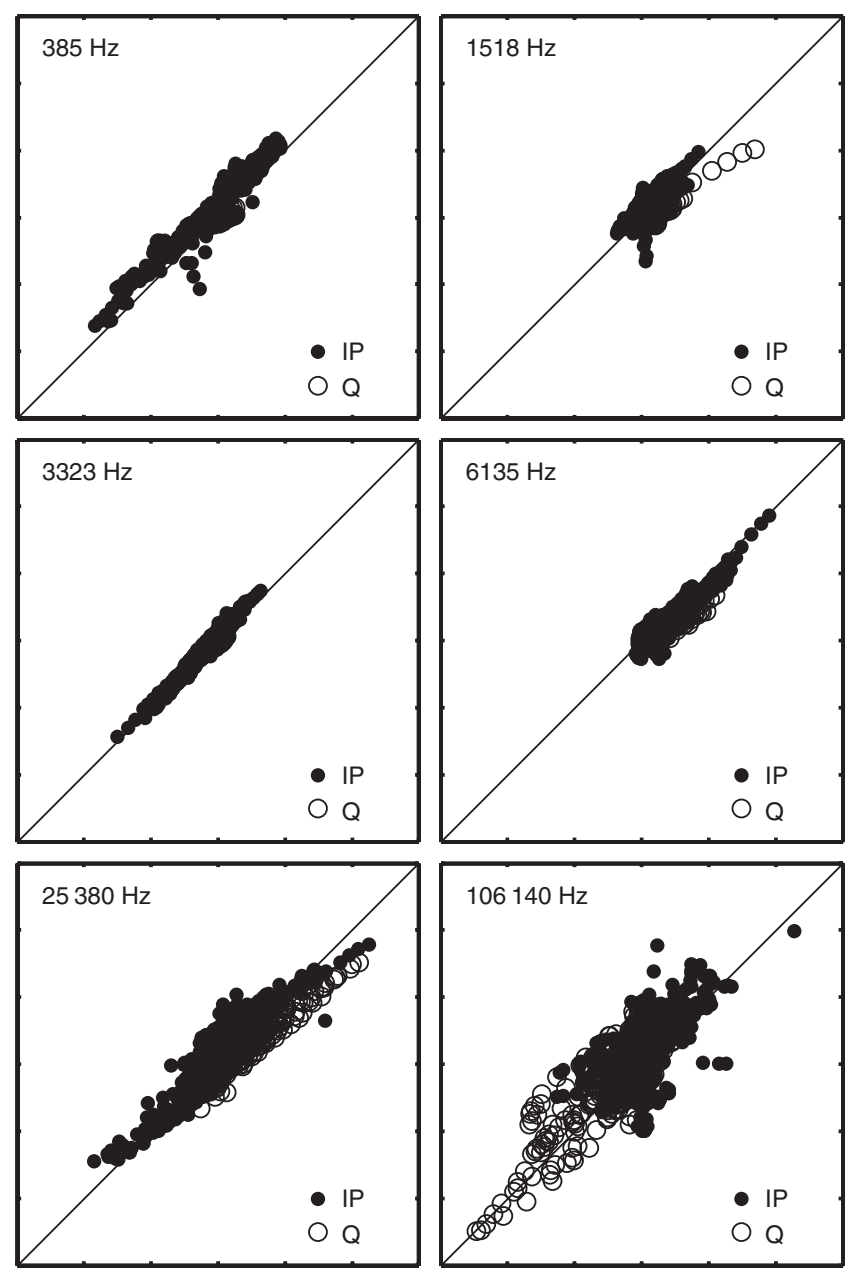

Fig. 3. Observed high altitude zero-levels (horizontal axis) versus zerolevels estimated from the holistic inversion calibration model (vertical axis). All axes range from -300 to $300 \mathrm{ppm}$. 


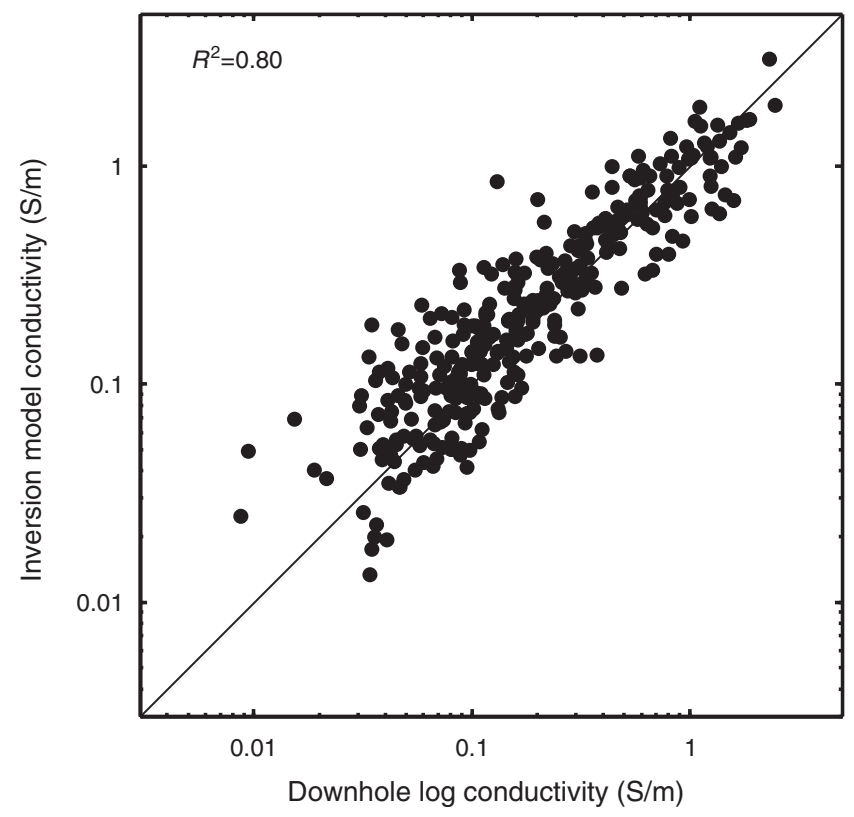

Fig. 4. A comparison of downhole log conductivity measurements and holistic inversion model conductivities.

the vertical smoothness constraints may have prevented a good estimation of some logs that have rapid changes (e.g. MTH8 and RIV9HC).

Figures 5 and 6 show the estimated conductivity of Layer 5 and Layer 12 in the holistic inversion model respectively. These images are almost totally free of any elongate anomalies coincident with the north-south flight lines. This suggests that the calibration model has adequately accounted for calibration effects in the raw data.

These conductivity images along with the conductivity-depth sections that are shown in Figure 8 are consistent with the conceptual geological model and prior information detailed by

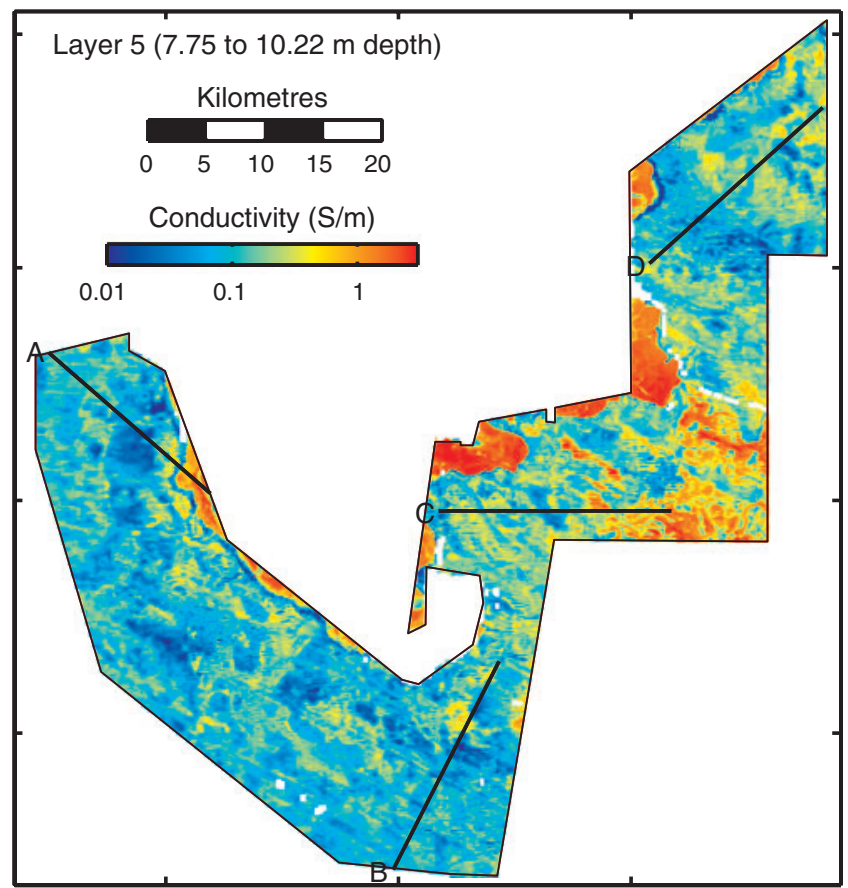

Fig. 5. Conductivity of Layer 5 (7.75 to $10.22 \mathrm{~m}$ depth) in the inversion model. Inversion model sections for lines A to D are shown in Figure 8.

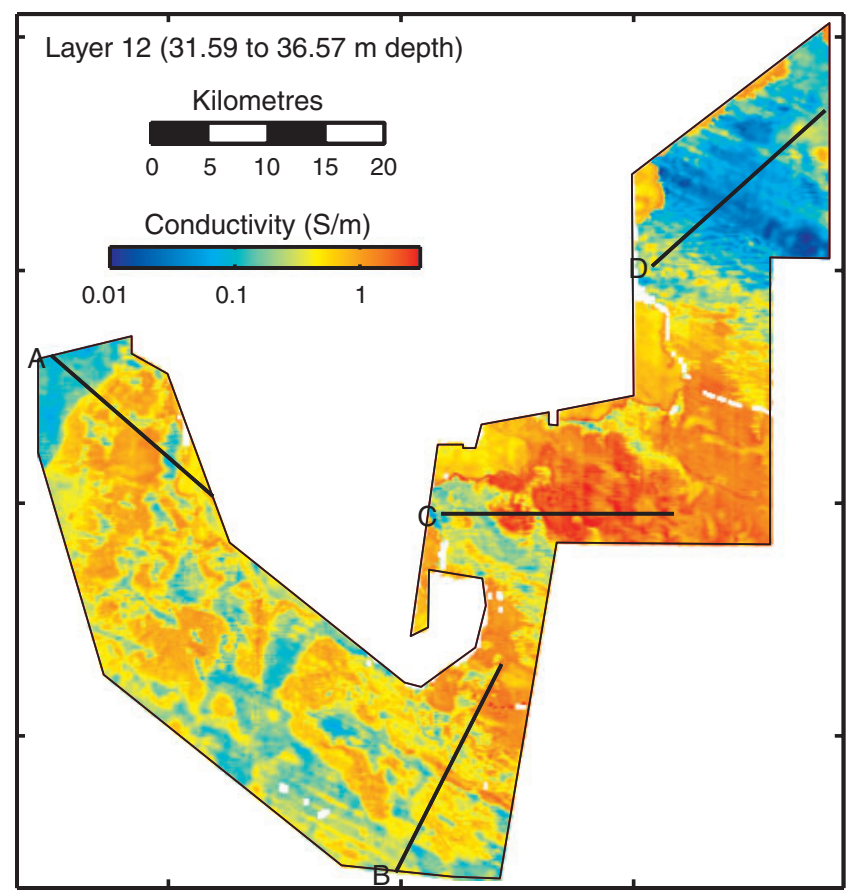

Fig. 6. Conductivity of Layer 12 (31.59 to $36.57 \mathrm{~m}$ depth) in the inversion model. Inversion model sections for lines A to D are shown in Figure 8.

Brodie et al. (2004b). Without using any of that prior knowledge the holistic inversion has revealed: (1) a saline watertable at depth, including a bulge (e.g. Section B) near its top; (2) a generally more resistive upper section where sand dunes and dry sands are expected; (3) a near surface conductor that is locally dissected; and (4) a strong north-west to south-east grain which is consistent with the existence of Pliocene strandlines.

Brodie et al. (2004b) generated a ground water elevation surface by gridding groundwater data from boreholes. This surface is plotted on the conductivity-depth sections and appears as a black line at $\sim 15-20$ m elevation. It is noteworthy that the groundwater elevation surface correlates well with the section's pronounced rapid conductivity increase (yellow-orange transition) at depth. We thus believe that the conductivity model provides an effective means of mapping the elevation of the saline watertable. An apparently anomalous conductive zone is evident above the water table surface at $17000 \mathrm{~m}$ on Section C (Figure 8). Mineralogical analysis by Tan et al. (2004) of materials from bore RIV9HC, which intersects the edge of the anomaly, indicated that this anomaly is due to highly conductivity kaolinitic clay between 4 and $16 \mathrm{~m}$ depth that sits above the water table which is at $22 \mathrm{~m}$ depth. This is confirmed by the conductivity log shown in Figure 7.

\section{Summary and conclusions}

It had previously been demonstrated that the holistic approach was an objective means of overcoming the weaknesses of in-field calibrations and subjective processing decisions that result in data that cannot be fitted with plausible conductivity models. However, it had only been demonstrated in cases where substantial prior information was available.

The alternative formulation presented here was implemented and run without using any survey-area specific prior data whatsoever. The resulting calibration model parameters are consistent with independent methods of deriving calibration parameters. Since the bias estimated from the inversion correlates well with the zero-levels observed at high-altitude, 

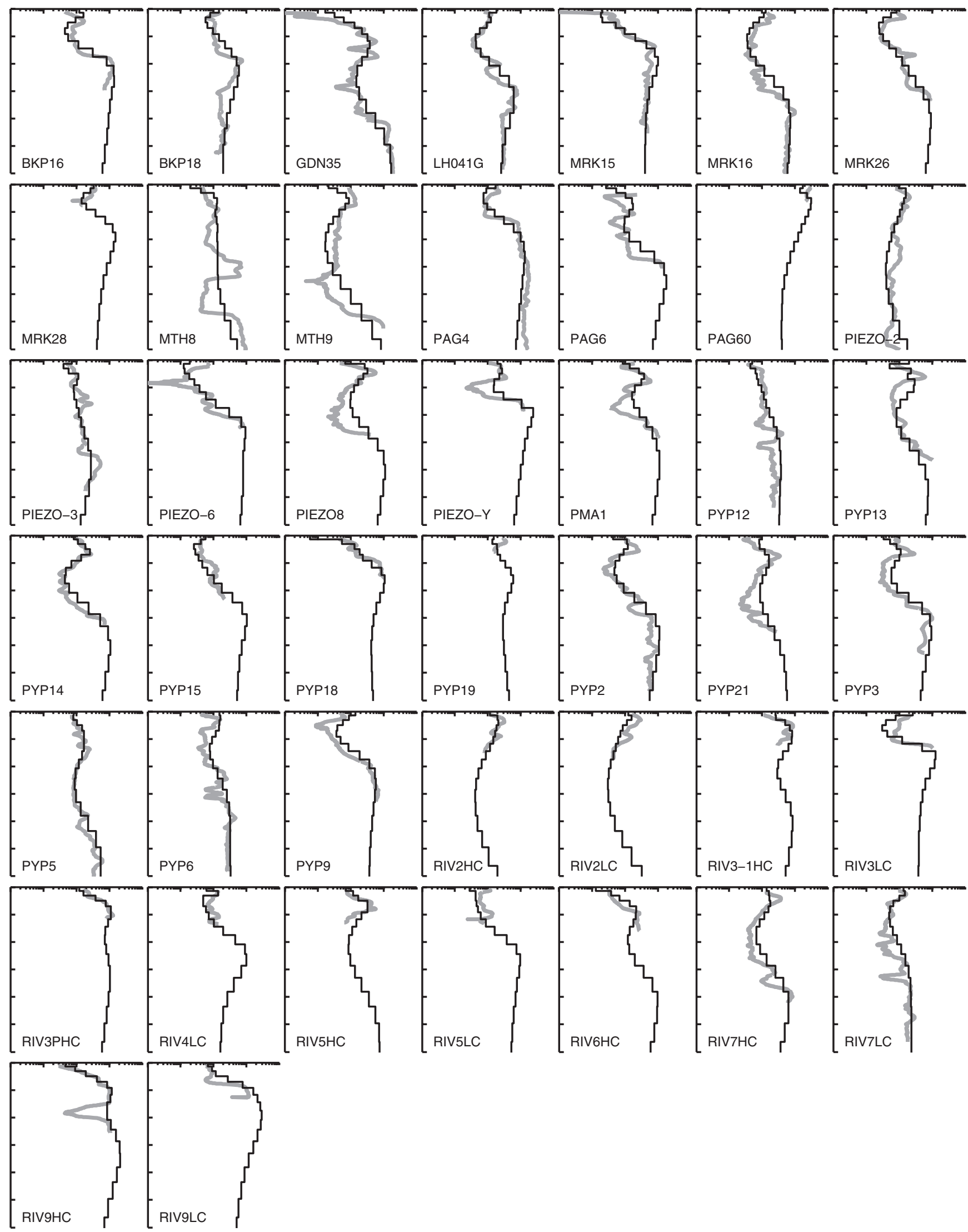

Fig. 7. Comparison of the 42 downhole conductivity logs (grey line) in the survey area and the conductivity model estimated from the holistic inversion (black line). Note that none of these logs (or any others) were used in the inversion, but the inversion is able to recover most profiles well. On all plots the vertical axis ranges from 0 to $60 \mathrm{~m}$ depth and the logarithmic scale horizontal axis ranges from 0.001 to $10 \mathrm{~S} / \mathrm{m}$. 


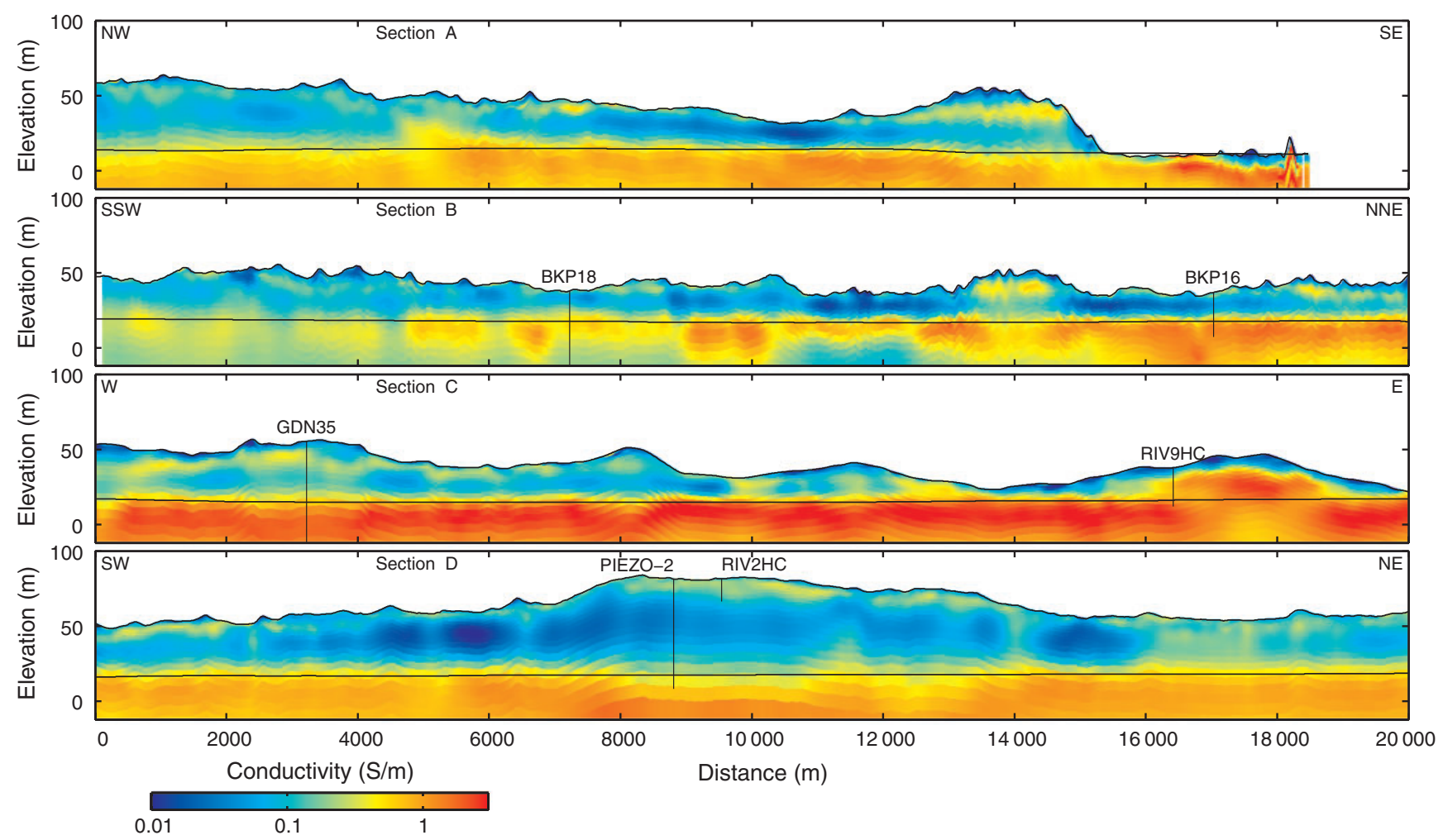

Fig. 8. A selection of conductivity sections through the holistic inversion model. The locations of the sections are shown on Figures 5 and 6 . Any boreholes that have downhole conductivity logs and are within $300 \mathrm{~m}$ of a section have been indicated on the section. The top of the watertable surface is shown by the black line at 15-20 m elevation.

we believe that there is potential for high altitude observations to be eliminated completely with associated cost saving in acquisition. The resulting conductivity model correlates well with downhole log conductivity data and conceptual geological models. It has also mapped the watertable elevation satisfactorily.

These results demonstrate that the holistic approach is not reliant on a sophisticated conceptual model or direct inclusion of survey-area specific prior conductivity information. The 'softer' regularisation constraints that were used might be expected to be applicable in a broad range of situations. Our use of independent prior information to assess the accuracy of the results has however provided extremely valuable feedback on the suitability of the parameterisation and constraints used for the specific example presented in this paper.

The success of this work should not be interpreted as an argument for neglecting prior information in AEM inversions. On the contrary, the information that is recovered from an inversion is always enhanced by appropriate prior information, and indeed we would always prefer it to be available and used as we did in Paper 1. However, here we have demonstrated the suitability of our algorithm in the less desirable situation where explicit prior information is lacking.

\section{Acknowledgments}

The Riverland data were acquired by the South Australian Salinity Mapping and Management Support Project, which is jointly funded by the Commonwealth and South Australian Governments under the National Action Plan for Salinity and Water Quality. We thank that Project for permission to publish this work. The inversions were carried out on the Terrawulf computational facility which is supported through the AuScope initiative. AuScope Ltd is funded under the National Collaborative Research Infrastructure Strategy (NCRIS), an Australian Commonwealth Government
Programme. We also thank Geoscience Australia for supporting this research. Brodie publishes with the permission of the CEO of Geoscience Australia.

\section{References}

Balay, S., Buschelman, K., Eijkhout, V., Gropp, W. D., Kaushik, D., Knepley, M. G., McInnes, L. C., Smith, B. F., and Zhang, H., 2005, PETSc Users Manual: Technical Report, Argonne National Laboratory, ANL-95/11-Revision 2.3.0.

Beamish, D., 2002, The canopy effect in airborne EM: Geophysics, 67, 1720-1728. doi: 10.1190/1.1527073

Brodie, R. C., Green, A. A., and Munday, T. J., 2004a, Calibration of RESOLVE airborne electromagnetic data - Riverland and East Tintinara, South Australia: Cooperative Research Centre for Landscapes, Environment and Mineral Exploration, Open file report 173.

Brodie, R. C., Green, A. A., and Munday, T. J., 2004b, Constrained inversion of RESOLVE electromagnetic data - Riverland, South Australia: Cooperative Research Centre for Landscapes, Environment and Mineral Exploration, Open file report 175.

Brodie, R. C., and Lane, R., 2003, The importance of accurate altimetry in AEM surveys for land management: Exploration Geophysics, 34, 77-81. doi: 10.1071/EG03077

Brodie, R., and Sambridge, M., 2004, Holistically calibrating, processing and inverting frequency-domain AEM surveys: Preview, 111, 100.

Brodie, R. C., and Sambridge, M., 2006, A holistic approach to inversion of frequency-domain airborne EM data: Geophysics, 71, G301-G312. doi: 10.1190/1.2356112

Constable, S. C., Parker, R. L., and Constable, C. G., 1987, Occam's inversion: a practical inversion method for generating smooth models from electromagnetic sounding data: Geophysics, 52, 289-300. doi: 10.1190/1.1442303

Deszcz-Pan, M., Fitterman, D. V., and Labson, V. F., 1998, Reduction of inversion errors in helicopter EM data using auxiliary information: Exploration Geophysics, 29, 142-146. doi: 10.1071/EG998142

Dongarra, J., Lumsdaine, A., Pozo, R., and Remington, K. A., 1994, A Sparse Matrix Library in $\mathrm{C}++$ for High Performance Architectures: Proceedings of the Second Object Oriented Numerics Conference, 214-218. 
Fitterman, D. V., 1998, Sources of calibration errors in helicopter EM data: Exploration Geophysics, 29, 65-70. doi: 10.1071/EG998065

Green, A., 2003, Correcting drift errors in HEM data: Preview, 102, 84.

Green, A., and Lane, R., 2003, Estimating noise levels in AEM data: Preview, 102, 70 .

Huang, H., and Fraser, D. C., 1999, Airborne resistivity data levelling: Geophysics, 64, 378-385. doi: 10.1190/1.1444542

Ley-Cooper, Y., and Macnae, J., 2004, Model-consistent rescaling to correct amplitude calibration problems in HEM data: Exploration Geophysics, 35, 277-282. doi: 10.1071/EG04277

Menke, W., 1989, Geophysical data analysis: discrete inverse theory: Academic Press.

Message Passing Interface Forum, 1994, MPI: A message-passing interface standard: The International Journal of Supercomputer Applications, $\mathbf{8}$, $165-416$.
Tan, K. P., Munday, T., and Leaney, F., 2004, The validation of resolve helicopter EM data: Mineralogical and petrophysical results from field investigations in the Riverland Area, South Australia: Cooperative Research Centre for Landscapes, Environment and Mineral Exploration, Open File Report 179.

Valleau, N. C., 2000, HEM data processing - a practical overview: Exploration Geophysics, 31, 584-594. doi: 10.1071/EG00584

\section{最小事前情報を用いた周波数領域空中電磁探査法データの総体的インバージョン}

\section{ロス ブロディ1・マルコム サムブリッジ2}

1 オーストラリア国立大学\&ジオサイエンスオーストラリア

2 オーストラリア国立大学 地球科学研究科

要 旨：周波数領域空中電磁探査法データに対する総体的インバージョン法は、これまで、事前情報が利用できる場合に、 取得データの処理と逆解析を同時に実施し、それらを調節させるために採用されてきた。しかし我々は、明白な事前情報が利 用できない場合にも適用可能な手法として、別の手法を開発した。本手法は、鉛直方向に滑らかな多層電気伝導度モデル、単 純化したデータバイアスのパラメータ化、標高に基づく水平方向の平滑化、コンピュータクラスタによる並列化、これら全て を一体として取り扱う手法である。適用結果として、何ら事前情報を用いず、8 00 万個のデータから 340 万個のパラメータを インバージョンにより推定した。その結果は、独立に導出されたキャリブレーションパラメータ、孔井検層データ、地下水位 データと整合性のとれるものであった。我々の開発した総体的インバージョンの優位点は、複雑な概念モデルや調查エリア特 有の事前情報を直接的に組み込む必要がないことである。さらに加えれば、総体的アプローチは、システムのゼロレベル計測 に必要な高所飛行の必要性が少ないので、データ取得に要する費用を減じることができるかもしれない。

キーワード : 空中、キャリブレーション、電磁、総体的な、インバージョン, MPI, 並列化

\section{최소 사전정보를 이용한 주파수 영역 항공 전자탐사 자료의 HOLISTIC 역산}

Ross Brodie ${ }^{1}$, Malcolm Sambridge ${ }^{2}$

1 호주 국립 대학 \& Geoscience Australia

2 호주 국립 대학, 지구과학연구과

요 약: 주파수 영역 항공 전자탐사 자료의 holistic 역산은 사전정보가 충분한 경우에 측정 자료의 보정, 처리 및 역산을 동시에 진행하는 역산법으로 개발되었다. 이 연구에서는 사전정보가 없는 경우에도 적용 가능하도록 holistic 역산을 발전시킨다. 이 역산에서는 수직방향으로 전기적 물성이 부드럽게 변화하는 다층 구조를 가정하고, 시스템 오차로 인한 편향 매개변수를 단순화하며, 고도에 따른 수평 방향의 평활화 조건을 적용하고, 클러스터를 이용하여 병렬 계산을 수행한다. 사전정보를 전혀 이용하지 않고 holistic 역산법으로 800 만 개의 자료를 340 만 개의 매개변수에 대해 역산한 결과, 이와는 별개로 계산된 보정 계수, 다운홀 로깅 자료 및 지하수위 자료와 잘 일치하는 결과를 얻을 수 있었다. 이로부터 holistic 역산의 성공 여부가 정교하게 작성된 초기 모형이나 탐사 지역의 특별한 사전정보와는 무관함을 알 수 있었다. 또한, holistic 역산은 높은 고도에서의 원점 측정을 필요로 하지 않으므로 자료 획득에 필요한 비용을 상당히 절감할 수 있을 것이다.

주요어 : 항공, 보정, 전자, 통합, 역산, $\mathrm{MPI}$, 병렬화 